\title{
POETAS E LITERATOS DA LIGÚRIA
}

\section{Luigi Castagnola}

(Universidade do Paraná)

Quando estudava literatura grega nos famosos "Elementos" de R. C. Jebb, li no manual do erudito historiador inglês, cuidadosamente traduzido em italiano por C. Fumagalli, uma afirmação que não deixou de me intrigar.

Os Jônios, e em especial os Áticos, comparados às abelhas pela suavidade da linguagem e da poesia, doces como o mel, haviam sido educados para a poesia pelas lindas paisagens do mar, das ilhas, das praias, das enseadas, das montanhas, dos vales e pelo céu azul da Grécia. Evidentemente, eram apontadas muitas outras causas da grandeza poética dos Jônios, mas as belezas naturais eram indicadas como fator ponderável e não último.

Não quis pôr em dúvida essa afirmação, que outro não menos famoso historiador da literatura grega, $V$. Inama, desta vez um italiano, confirmava na vigésima terceira edição de seu manual de Literatura Grega. E penso que infindos outros historiadores das letras gregas, igualmente famosos, tenham sustentado a mesma opinião. Não sòmente não duvidava dessa afirmação, mas parecia-me até muito natural que assim fôsse. Entretanto, como disse, a coisa não deixou de me intrigar. E o motivo é o seguinte.

Estudava, no mesmo tempo, também literatura italiana, isto $\dot{e}$ a literatura que floresceu nas diversas regióes da peninsula Itália, que Francisco Petrarca definiu com harmonioso verso:

\section{II bel paese}

ch'Appennin parte e 'l mar circonda e l'Alpe.

Ora, entre as regiões da Itália, há uma que, por opinião comum dos viajantes e dos homens de letras, é um verdadeiro paraíso: a Ligúria. É bem conhecida pelos turistas do Novo Mundo que, todos os dias, desembarcam no pôrto de Gênova, bem 
como pelos Europeus, especialmente alemāes e suíços, que, no verão, como bandos de aves migratórias, invadem a Riviera, levantando por tôda parte "campeggi", como diziam outrora, ou "autostelli", como dizem agora. E os italianos do interland piemontês e lombardo quase não podem passar sem a "villeggiatura in Riviera". Napoleão e Cambetta, O'Connel e Cromwell, Verdi e Wagner, Dickens e Byron, Rubens e Van Dyck, e até o superhomem Nietzsche não encontravam palavras suficientes para louvar Gênova e a Riviera. Wagner dizia nunca ter visto coisa mais formosa; Nietzsche chamou de fantásticos aquêles lugares construidos por homens loucos pelo sol e pelo mar; Schiller num dos Fieschi achou o drama passional que empolgou seu coração romântico, e Colombo escrevia no auge de sua glória ao povo genovês: "Bien que el cuerpo ande acá, el corazón está allí de continuo".

Pois bem, apesar de tantas belezas naturais, apesar do mar encantador, apesar do sol, das enseadas, das praias, das flôres, das montanhas e dos vales, além do clima que Deus deu de presente aos habitantes da Ligúria, esta encantadora regiāo da Itália nunca produziu um grande poeta ou um escritor de primeira ordem. Nem nos longínquos tempos da latinidade, quando o manso Virgilio chamou o povo ligure de "durum genus" e "adsuetum malo", raça dura, áspera e acostumada ao trabalho mais penoso.

Ainda mais. A Itália teve gloriosos poetas dialetais, Trilussa. Di Giacomo, Belli, Porta, mas nenhum dêles é lígure. Para demonstrar que nenhum grande poeta ou literato italiano nasceu na Ligúria, é suficiente pensar que Dante, Petrarca e Boccaccio sāo toscanos - aliás a Toscana teve sempre a parte do leão na literatura italiana; Poliziano é de Montepulciano, Sannazaro de Nápoles, Boiardo de Scandiano, Machiavelli de Florença, Ariosto de Réggio Emília, Tasso de Sorrento, Metastásio de Roma, Goldoni de Veneza, Parini é lombardo, Alfieri piemontês, Monti é de Romanha, Fóscolo é veneziano, Manzoni é lombardo, Leopardi é de Recanati, Carducci é toscano, Páscoli é de São Mauro, Fogazzaro não é lígure e Verga é siciliano; De Sanctis, D'Annúnzio, Pirandello, Papini, Croce e Panzini também não sāo ligures. 
Mas deixando de lado os gigantes da literatura italiana, mesmo entre os poetas menores e os prosadores de segunda ordem, um lígure é rara avis. Guinizelli, Cavalcanti, Angiolieri, Guittone, Sacchetti, Cavalca, Passavanti, Compagni, podemos dizer todos os humanistas, Pontano, Lourenço de Médicis, Pulci, Bembo, Tríssino, Castiglione, Guicciardini, Folengo, Aretino, Bandello, Marino, Cellini, Sarpi, Vico, Gozzi, Colletta, Péllico, Guerrazzi, D'Azéglio, Cantú, Giusti, Tommaseo, Gioberti, Nievo, Balbo, Amari, Zanella, Fucini, Collodi, Deledda, Cecchi, Baldini, Bacchelli, Cicognani, Ungaretti e muitos outros formam um verdadeiro exército literário, onde inùtilmente procuraremos um nome lígure.

Se as belezas naturais da Grécia haviam educado para a poesia os Jônios, por qual motivo as belezas naturais da Ligúria não tiveram o mesmo poder? Achava que os historiadores da literatura grega não deviam estar sem alguma razão, mas o caso da Ligúria deixava-me desapontado.

Desde as origens da literatura italiana até hoje não se encontram duas dúzias de escritores lígures, e nenhum dêles ocupa lugar de destaque nas letras italianas. As demais regióes da Itália, no conjunto, de poetas e prosadores da envergadura dos da $\mathrm{Li}$ gúria têm mais de um milheiro. $O$ que se nota, entretanto, é que na Ligúria aumentou o interêsse pela poesia e pela literatura nestes últimos tempos.

Deixamos aos escritores lígures ou italianos dizerem-nos os motivos da pobreza literária da Ligúria, um dos mais explêndidos recantos do planêta. Sabemos que o Ligure é um dos povos mais antigos da Europa, se é verdade o que afirmam os antropólogos e os linguístas; sabemos que a Ligúria é a região relativamente mais povoada da Itália, que Gênova foi uma república gloriosa e o povo lígure foi sempre extraordinàriamente ativo e empreendedor, teimoso e inquebrantável pelos caminhos do mundo. Não sabemos porque produziu tão pouco no campo literário. Talvez tenha preferido dedicar suas energias e entusiasmo aos negócios rendosos, aos comércios, às viagens oceânicas, aos empreendimentos utilitários das organizações bancárias e industriais? Ou então, vivendo num paraiso terrestre, achou que não pre- 
cisava construir fantásticos mundos poéticos, por julgá-los inúteis a quem vive já na realidade encantadora do sol, das paisagens floridas e do mar? Sòmente êles o sabem (1).

Eis os nomes dos poetas e dos literatos da Ligúria que se encontram nas eruditas histórias da literatura italiana: Lanfranco Gigala, lácopo da Varazze, Gabriello Chiabrera, Giovanni Marini, Giúlio Brígnole Sale, Innocenzo Frugoni, Goffredo Mameli, Giuseppe Mazzini, Giovanni Ruffini, Giúlio Barrili, Césare Abba, Paolo Giacometti, Edmondo De Amicis, Ángiolo Sívio Novaro, e - grupo dos modernissimos: Ceccardo Roccatagliata, Camillo Sbarbaro, Pietro Jahier, Adriano Grande, Eugênio Montale, Francesco Pastonchi, Carlo Bo, Italo Calvino (2).

Como se pode ver, após os raros antigos, temos que chegar ao século XVI para encontrar um literato ligure; uns poucos aparecem em Seiscentos e Setecentos. Os outros constituem o grupo dos literatos patriotas do "Ressurgimento Italiano"; por último vem o grupo dos poetas e literatos contemporâneos. Sòmente Mazzini e De Amicis sāo nomes conhecidos em todo o mundo, mas nem um nem outro por motivos exclusivamente literários.

Lanfranco Gigala (séc. VIII), genovês, é o trovador que mais se distinguiu na Ligúria. No comêço realista e sensual, acabou idealista e católico; inimigo do "trobar clus", foi chamado poeta cristalino e do sorriso por Segismundo Spina. Estudou direito, foi conselheiro da República e também embaixador, sendo assassinado perto de Mônaco, em 1278. Na mocidade cantou a formosura de Berlenda Cibo e de outras damas, sofrendo paulatinamente uma evolução em sentido cristão e ascético que o levou a composições poéticas de caráter mariano. No mesmo século floresceram ainda os trovadores genoveses Percivalle Dória, Calega Panzano e Bonifácio Calvo; os dois primeiros foram à Itália do sul, abraçando a causa do gibelinismo, o terceiro rumou para o Ocidente, estêve na côrte de Afonso $X$ de Castela e escreveu versos em português, voltando mais tarde à pátria.

lácopo da Varazze (1230-1298) foi frade dominicano e bispo de Gênova, homem bondoso e culto, historiador e hagiógrafo muito conhecido e lido na Idade Média. Deixou um volume de 
Sermones e o Chronicon Januense. Entretanto, o que 0 tornou famoso como literato foi a Legenda aurea, onde o escritor conta gestas de santos sem grande preocupação crítica, mas com estilo vivo e encantador. Ainda hoje êste livro é lido com prazer, especialmente na vulgarização feita recentemente por Arrigo Levasti.

Gabriello Chiabrera (Savona, 1552-1638) gozou de grande fama na sua época e ainda Parini, Fóscolo, Leopardi e Carducci o apreciaram, mas a crítica moderna, podemos dizer unânimemente, acha em Chiabrera não lirismo pindárico e inovações criadoras, e sim artifícios de palavras. Como Colombo, queria "trovar nuovo mondo o affogare"; por isso, quis renovar as letras italianas, tentando, antes de Carducci, reproduzir $e$ introduzir na poesia italiana a assim chamada "métrica bárbara" imitando os clássicos antigos.

Após uma mocidade bastante agitada, impetuosa e briguenta, tornou-se um cavalheiro ambicionado pelas côrtes que o recebiam e tratavam principescamente, embora, sendo rico e nobre, tenha preferido levar vida independente e livre.

Escreveu os poemas Cotíade, Firenze, Foresto, Amedéide; as tragédias Ermínia e Angélica in Ebuda. Obras falidas e, em parte, de imitação a Tasso e Ariosto. Escreveu ainda o melodrama Rapimento di Cefalo e outras composições dramáticas: Amore sbandito, II pianto d'Orfeo, Orizia, Alcippo, Megarina, Gelopea. Entretanto, a parte poética de Chiabrera que mais impressionou foi a lírica: Rime, Canzoni (diversos volumes). Lembramos ainda: Poemetti profani, Poemetti sacri, Sermoni em versos brancos, um Ditirambo, Vendemmie di Parnaso e sete Egloghe.

Em prosa escreveu a Autobiografia, os Dialoghi sôbre a arte poética e uns volumes de Lettere.

Como se vê, Chiabrera foi muito ativo e sua produção literária é volumosa. E certamente uma figura interessante do mundo literário da época, mas seu valor artístico é escasso, embora a crítica moderna pise severa demais sôbre o poligrafo savonês. 
Suas "canzonette" tiveram muita fortuna e comparecem ainda hoje nas antologias italianas. Eis algumas estrofes famosas:

Belle rose porporine,

Che tra spine

Sull' aurcra non aprite,

Ma, ministre degli Amori,

Bei tesori

Di bei denti custodite...

Se bel rio, se bell'auretta

Tra l'erbetta

Sul mattin mormorando erra:

Se di fiori un praticello

Si fa bello,

Noi diciam: - Ride la terra.

Quando avvien che un zefiretto

Per diletto

Bagni il piè nell'onde chiare,

Sicché l'acqua in sull'arena

Scherzi appena,

Noi diciam che ride il mare.

Se giammai tra fior vermigli,

Se tra gigli

Veste l'alba un aureo velo,

E su rote di zaffiro

Move in giro,

Noi diciam che ride il cielo.

Giovanni Marini (1594-1650), genovês, tornou-se conhecidíssimo na sua época por ter publicado o romance Colloandro, heróico e galante. Embora divulgado em tôda Europa, imitado por La Calprenéde e lido por Gautier, após ter despertado o riso de Baretti e Coldoni, foi desmontado para sempre por Carducci; nem as pálidas defesas de Albertazzi conseguiram salvar do eterno esquecimento o romance e seu autor, que os contemporâneos proclamaram "sublime e imortal". 
Antón Giúlio Brígnole Sale (1605-1665), genovês, de família ilustre e nobre, foi cidadão distinto pelo caráter e pela cultura. Van Dyck retratou o fidalgo patrício lígure num quadro que embeleza a galeria do "Palazzo Rosso" de Gênova. Escreveu catorze obras, sendo a principal intitulada Instabilità dell'Ingegno (1635). É uma narração mista, em prosa e verso, longínqua imitação do Decamerone. Quatro donzelas e quatro moços, para escapar ao contágio da peste, retiram-se para um castelo; o escritor conta os divertimentos honestos a que se abandona por oito dias a fidalga comitiva e conta outrossim cinco novelas. Marinista no comêço, o fidalgo e ajuizado escritor passa paulatinamente a hostilizar o marinismo, tão dominante no seiscentismo italiano.

Innocenzo Frugoni (1692-1768) foi também êle genovês, mas viveu quase sempré na côrte dos duques de Parma, tendo antes lecionado em diversas cidades da Itália. Escreveu canções heróicas e sonetos históricos, tornando-se muito conhecido pelo uso do verso branco. Monti louvou Frugoni por esta novidade, - mesmo fêz Bettinelli, mas Baretti nada via de original e criador na torrencial produção de versos brancos dêste poeta. Pompeati viu em Frugoni um pseudo-poeta que explorou em sentido utilitário a sua musa. Cantou, de fato, tôda espécie de acontecimentos para fins encomiásticos; dez volumes abrangem suas poesias laudatórias, relativas a pessoas e coisas da côrte: nascimentos, casamentos, aniversários, formaturas, falecimentos, curas, etc., bem como cantou pássaros, cachorros de estimação, gatos, galos et similia. No fim de sua vida o próprio poeta reconheces a inutilidade de seu labor poético.

Paolo Giacometti (1816-1882) nasceu em Novi Lígure e escreveu nada menos de oitenta dramas; faltou-lhe, porém, o gênio de Goldoni. Hoje ninguém mais lê os dramas de Giacometti, salvo um ou dois, que ainda interessam mais pelo conteúdo do que pela forma artística. Escreveu também um tratado cujo titulo é: Della letteratura drammatica in Italia.

Chegamos ao grupo dos que se poderiam chamar os poetas e os literatos do "Ressurgimento Italiano": Mameli, Mazzini, Ruffini, Barrili, Abba e De Amicis. São nomes, sem dúvida, ainda hoje 
caros aos Italianos, porque ou lutaram ou morreram ou escreveram com ardor patriótico ou patético afeto sôbre os sofrimentos da Itália de então, e muito contribuiram, também com a pena e com a poesia, para as lutas politicas, as revoluções $e$ as guerras que visavam alcançar a unidade e a independência políticas da Itália, que, de fato, se realizaram em 1870. Por isso, especialmente os nomes de Mameli, Mazzini e De Amicis são muito conhecidos na Itália, mas o verdadeiro motivo da fama dêsses autores é mais político do que literário.

Coffredo Mameli (1827-1847) nasceu em Gênova, sendo seu pai um oficial da Marinha, Jorge Mameli, de nobre familia da Sardenha, e sua mãe a ligure Adelaide Zoagli. Goffredo estudou direito na Universidade de Gênova, mas dedicou-se à poesia e às lutas politicas, falecendo ainda moço depois de ter sido gravemente ferido em batalha pela independência italiana. Foi assim truncada sua carreira literária, que muito prometia. Em 1846 escrevia o canto da Alba (Alvorada), despertando nos Italianos as esperanças de libertação nacional, $€$ no ano seguinte ditou em Gênova o famoso hino, que se tornaria o Hino Nacional:

Fratelli d'Italia,

L'Italia s' è desta.

Mazzini prefaciava, em 1850, a primeira edição das poesias di Mameli; a última edição foi publicada por Codignola Arturo, em 1927, por ocasião do primeiro centenário do nascimento do poeta soldado. Nāo foi grande a produção literária de Mameli, pois, como dissemos, faleceu bem moço, quando não tinha alcançado ainda sua madureza artística; entretanto imensa foi a fascinação que alguns seus hinos exerceram sôbre as jovens geraçōes da Itália. Verdi compôs a música do hino All' armi all'armi e No varo Miguel escreveu a música do impetuoso hino Fratelli d'Italia.

Giuseppe Mazzini (1805-1872) nasceu em Gênova; seu pai, Jácomo, era professor de anatomia na Universidade de Gênova e teve também influência politica na sua cidade; a mãe, Maria Drago, foi inteligente e delicada alma feminina, tendo exercido profunda influência na educação religiosa e cívica de Mazzini. 
Estudou também êle direito, mas suas paixões foram a literatura e a política. Na história do "Ressurgimento Italiano" Mazzini é uma das figuras mais marcantes; podemos dizer que foi a chama viva que alimentou, de um modo ou de outro, tôdas as polêmicas, as revoluções, as guerras e os movimentos políticos da Itália de sua época e não foi pouca sua atuação também na política da Europa de então. Fundou a Giovane Italia, a associação e o relativo periódico, a Giovane Europa, e La leune Suisse; sofreu diversos desterros por motivos políticos, foi prêso e perseguido várias vêzes, mas sempre conseguiu voltar às lutas políticas e sociais, fundando revistas, chefiando revoltas de caráter político e social. Foi também deputado e triúmviro da República Romana, ocupou-se com o melhoramento da vida dos trabalhadores, hostilizando a teoria marxista do materialismo econômico, pois julgou que a transformação social em proveito do povo é impossivel sem a formação moral, cívica e religiosa do povo. Daí suas frases famosas: "Unidade e República" (contar os monarquistas), "Deus e Povo" (contra os materialistas), "Pensamento e Ação" (para a organização de uma sociedade melhor).

Mazzini foi um grande idealista, nem tôdas suas idéias foram igualmente fecundas e, embora espírito naturalmente religioso, sua visão religiosa teve mais caráter humanitário e iluminista do que católico.

A formação literária de Mazzini foi vasta e profunda; seus autores preferidos foram Dante, Shakespeare, Byron, os EvangeIhos e a Bíblia, Alfieri, Fóscolo, Tácito, Ésquilo, Hegel, Kant, Vico, Cuoco e Herder.

As obras de Mazzini foram publicadas várias vêzes e ainda não foi levada a têrmo a Edição Nacional, que deveria abranger mais ou menos vinte volumes. Mazzini serviu-se da palavra escrita para espalhar sua mensagem política e social, mas também distinguiu-se por estudos literários, tratando até de literatura européia. Mencionaremos aqui seus escritos que têm especial caráter literário. Em Londres escreveu ensaios e críticas literárias, publicados depois em Lugano, na Suiça, em três volumes. Notável é o ensaio Dell'amor patrio di Dante, e importante é o prefácio 
da edição dos Scritti politici inediti di Ugo Fóscolo; muito louvada foi também a Filosofia della Musica. Deixou muitas Lettere e Note autobiografiche; seu severo conceito da vida e do dever é exposto em Doveri dell'uomo. Como dissemos, fundou os periódicos La Giovane Italia e cutros que pretendiam divulgar sua mensagem política e social pela Europa; numerosos artigos seus apareceram em L'apostolato, L'Italia del Popolo, por êle fundados, e na Antologia.

O estilo de Mazzini é um tanto oratório, sua prosa não conhece as variações e o tom é profético e sonoro; o lirismo messiânico da prosa maziniana, a ênfase declamatória e tribunícia impressionaram os leitores da época, mas não agradam mais hoje em dia.

Giovarni Ruffini (Gênova 1807 - Tággia 1881), foi um dos partidários de Mazzini e por motivos políticos teve que ir para o exílio na Suiça e depois em Londres e Paris, vivendo longos anos na capital inglesa. Em seguida foi deputado do parlamento suba!pino, quando Gioberti mandava na política piemontesa. $\mathrm{Na}$ inglaterra fêz conhecer aos Ingleses as idéias que animavam os Italianos, despertando simpatias pela independência de sua pátria. Teve dois irmãos também literatos e políticos Jácomo e Agostinho; o primeiro, ao que parece, suicidou-se no cárcere, em Gênova, depois de ter sido prêso por motivos políticos; o segundo fugiu para o exilio, na Inglaterra e na França, passou alguns anos em Edimburgo e voltou depois à pátria. Ambos foram fautores das idéias românticas.

Ruffini possuia perfeitamente $o$ ingiês, e nesta língua escreveu cinco romances, sendo os dois principais: Lorenzo Benoni, or passages in the life of an Italian, $e$ Dottor Antonio. Tanto um como o outro tem caráter autobiográfico, sem ser entretanto autobiografias. Escreveu também o "libretto" do Don Pasquale para seu amigo Donizetti, que o musicou. Ruffini demonstra grande habilidade em descrever a "Riviera Lígure", que amava profundamente, e serviu não pouco para atrair correntes turísticas inglesas para a Ligúria. 
Antônio Giúlio Barrili (Savona, 1836 - Cárcare, 1908) foi jornalista apreciado e romancista; acompanhou Garibaldi como voluntário, foi professor de literatura italiana na Universidade de Gênova, da qual foi também Reitor. Seu Discorso in morte di Garibaldi foi muito e merecidamente elogiado; a Garibaldi dedicou ainda um livro, Con Garibaldi alle porte di Roma. Escreveu romances psicológicos e históricos; romances históricos são os quatro que formam o ciclo colombiano e Semiramide; dos romances psicológicos mencionamos L'olmo e l'edera, Santa Cecilia, Val d'olivi, Come un sogno.

Giuseppe Césare Abba (Cairo Montenotte, 1838 - Bréscia, 1910) foi soldado garibaldino, escritor, poeta e professor. Após ter tomado parte na famosa expedição de "I Mille' e em outras guerras garibaldinas, retirou-se para seu torrão natal, escrevendo livros e poesias, que the mereceram o convite para lecionar literatura italiana.

Além de artigos e discursos, escreveu: Vecchi versi, Storia dei Mille, Vita di Nino Bixio e outras coisas menores. Mas o que the deu fama foi o livro Noterelle d'uno dei Mille edite dopo vent'anni, um diário lírico e vivo, embora um tanto "costruito" como diria Croce, considerado justamente um dos mais belos livros de tôda a literatura garibaldina.

Edmondo De Amicis (Onéglia, 1846, - Bordighera, 1908) é - escritor lígure mais conhecido na Itália e no estrangeiro. Na mocidade foi oficial do exército; convidado a dirigir, em Florença, L'Italia Militare, resenha do Ministério da Guerra, nela publicou muitos contos de vida militar, que, enfeixados em volume, the deram grande popularidade. Resolveu então abandonar a vida militar para se dedicar sòmente à atividade literária. Fêz diversas viagens ao estrangeiro; na Itália viveu longamente em Turim e foi convidado a fazer parte do "Consiglio Superiore delI'Istruzione"; teve então ocasião de visitar muitas vêzes Roma e também Florença, sede da Academia da "Crusca", de que era membro. Admirador de Manzoni, procurou imitar-lhe o sentido humano da vida e o programa literário; entretanto De Amicis nem sequer de longe pode ser comparado ao grande lombardo. Visita- 
va freqüentemente a Riviera Ligure, sua pátria, e aí faleceu quase improvisamente, na graciosa cidade de Bordighera. Os últimos anos de sua vida foram profundamente amargurados por motivos de ordem familiar, e um seu filho suicidou-se. Interessou-se pela questão social e fêz propaganda de teorias socialistas, vendo nelas a possibilidade de melhorar a vida do povo, mas nunca se abandonou à violência, pregando sua mensagem humanitária entre os homens, imbuida de sentimentalismo um tanto artificial e ingênuamente otimista.

A produção literária de De Amicis foi grande, mas de não grande valor, nem têm importância seus estudos lingüisticos, absolutamente superficiais, embora expostos de modo agradável no Idioma Centile. Em geral, a literatura de De Amicis tem finalidade social e cívica, ainda que falte quase o fator religioso. Esforçou-se por retratar os aspectos bondosos da vida e dos indivíduos, convidando a todos para a prática da educação cívica; tôdas suas páginas são, podemos dizer, uma exortação ao amor à pátria. Faltou a De Amicis o gênio, mas assistiu-o contìnuamente o esfôrço literário. Escritor mediocre no ponto de vista artistico, teve entretanto eficácia não comum na formação humana do povo.

Mencionaremos seus principais trabalhos, sendo impossivel no âmbito dêste artigo analisá-los: Vita Militare, Novelle, Spagna, Olanda, Ricordi di Londra, Costantinopoli, Ricordi di Parigi, Sull'oceano, Le tre capitali: Torino, Firenze, Roma, Ritratti letterarii, Cli Amici, II romanzo d'un maestro, Fra scuola e casa, La maestrina degli operai, La carrozza di tutti, Nel regno del Cervino, Memorie, Lotte civili, Ricordi d'infanzia e di scuola, etc. Uns volumes foram publicados pòstumamente. Foi De Amicis um agradável escritor, mas nāo foi verdadeiro artista. No ambiente histórico de hoje a mensagem humanitária de De Amicis não desperta mais o interêsse de outrora. Suas coisas melhores são: Vita Militare, Gli Amici, Sull'oceano, e os livros de viagens.

Seria injustiça porém, negar que saiu das mãos de De Amicis um livro que educou muitas geraçōes de crianças na Itália e correu todo o mundo: II Cuore (O Coração). E a narração dos acon- 
tecimentos simples, humanos, infantis, populares de um ano de escola elementar; uma pequena epopéia infantil, onde os heróis são os alunos, filhos do povo, com suas travessuras, suas dores, seus sofrimentos morais, suas vitórias, suas boas açōes. No meio dêles Edmundo anda bondoso e paternal, como um novo Homero entre heróis humildes. Os famosos contos mensais fizeram chorar muitas crianças italianas e estrangeiras. Embora não șe trate de autênticas obras-primas artísticas, achamos que encerram valores incontestáveis, especialmente 0 Patriotazinho de Pádua, O Pequeno Vigia Lombardo, 0 Pequeno Escrevente Florentino, 0 Tamborzinho Sardo, Dos Apeninos aos Andes. Êste último é um dos mais famosos e sintetiza a constante atenção e a sensibilidade de De Amicis pelos humildes imigrantes italianos, obrigados a enfrentar imensos sacrifícios morais e materiais em terras longínquas para ganhar o pão de todos os dias, derramando lágrimas amargas e levando por tôda parte, até os Andes Americanos, a imensa saudade da pátria no coração (2).

Chegamos, assim, aos escritores e poetas da atualidade. Uns dêles já morreram, como Novaro, Ceccardi Roccatagliata, Pastonchi; outros são ainda vivos e atuantes para despertar no povo de sua terra o amor à poesia e o interêsse pela literatura. Mencionaremos os que tiveram maior projeção no mundo literário.

Ángiolo Sílvio Novaro (Diano Marina, 1866 - Impéria, 1938) foi cantor delicado e mesto de coisas humildes, um pouco à maneira de Páscoli; a poesia de Novaro, porém, não conhece $s^{0}$ mente o tema da saudade vaga e a fascinação do mistério, mas se deixa iluminar outrossim pela luz da esperança e da serenidade. Bem definiu seu mundo poético êle mesmo, quando escreveu:

La mia Musa cammina

Con un fiore montanino in bocca

Per mattini intirizziti d'argento....

Dorme sotto una pergola di stelle....

E nel sonno fantastica misteri

Di parole da dire a Dio, tutte belle....

Beve dell'acqua delle fontanelle....

E canta per grazia d'amore.... 
Ma qando ammutisce, e rimane A sedere sulla porta della sera.... Una tristezza che non sa che sia, Le prende il cuore:

Si rammenta d'un tempo e d'un bene Che il destino gli ebbe uccisi...

Pensa un cielo e una riva

Dove il cuore non il piede arriva.

Criou Novaro um mundo de afetos delicados e meigos, conseguindo evitar o sentimentalismo vazio e artificial; seus versos são nobres e sinceros, sabem cantar o mistério que atormenta todo homem, e contemplar com alegria as belezas do dia cheio de sol e as luzes das estrêlas que iluminam as noites profundas do cosmo e as do coração humano. Em 1929 entrou para a Academia da Itália.

Escreveu: Giovanna Ruta, romance; Manoscritto di una vergine, conto; Sul mare, novelas; II libro della pietà, novelas; e vários volumes de versos. Entre êstes mencionamos: La casa del Signore, II cuore nasconto, II piccolo Orfeo, La Madre di Gesú, que é uma síntese lírica da vida da Virgem Maria. Os dois livros mais conhecidos de Novaro são: Il Fabbro Armonioso, pequeno volume de memórias e confissões, em prosa, inspirado pela morte do único filho do poeta, desaparecido na primeira guerra mundial, e Cestello, coleção de poesias para crianças, mas que falam também ao coração e ao espírito dos adultos. Neste lindo livro de versos Novaro canta, com amor e saudade, entre as flôres, o sol, - mar, os vales e as montanhas da Ligúria, os sentimentos que fazem vibrar o seu coraçăo. Eis uma bela lírica inspirada ao poeta pelo cair argentino da chuva de março.

Che dice la pioggerellina de marzo, che picchia artentina sui tego!i vecchi del tetto, sui bruscoli secchi dell'crto, sul fico e sul moro crnati di gemmule d'oro? "Passata è l'uggiosa invernata, passata, passata! 
di fuor dalla nuvola nera,

di fuor dalla nuvola bigia

che in cielo si pigia,

domani uscirà primavera

gremito il grembiale

di lucido sole,

di fresche viole,

di primule rosse, di battiti d'ale,

di nidi,

di gridi

di rondini, ed anche

di stelle di mandorlo, bianche..."

Ceccardo Roccatagliata Ceccardi (1872-1919), genovês, foi considerado um dos mais notáveis poetas da Ligúria dêste século. Sofreu a influência de Carducci e D'Annunzio, bem como a de Verlaine, mas soube tornar-se independente e pessoal, nem chegou a ser poeta da vagabundagem. Escreveu, entre outras coisas, Libro dei frammenti, e Sonetti e Poemi.

Francesco Pastonchi (Riva Lígure, 1877 - Turim, 1953), foi aluno de Artur Graf na Universidade de Turim, onde lecionou também êle literatura italiana desde 1935. Jornalista apreciado e poeta um tanto artificial, teve grande fama pela sua habilidade em declamar poesias suas e de outros poetas. Escreveu: Simma, tragédia; II violinista, romance; II mazzo di gelsomini, II campo di guerra, Trasfigurazioni, livros de novelas e contos. Pastonchi grangeou maior fama como poeta, ainda que de não alto vôo. Lembramos seus livros de versos: Belfonte, Saffiche, Giostra d'amore, II pilota dorme, II Randagio, Nuove Italiche, Versetti.

Pietro Jahier (Gênova, 1884) tornou-se conhecido especialmente por um livro de guerra, Con me e con gli alpini; publicou o romance Ragazzo, Canti di soldati, e outras coisas. Fundou o jornal de guerra Astico e II Nuovo Contadino, e escritos seus apareceram em revistas e jornais suíços e franceses, bem como na revista Voce, distinguindo-se ainda como bom tradutor.

Camillo Sbarbaro (Santa Margherita Lígure, 1888), foi soldado e viajou pela Europa, embora tenha passado a maior parte de su vida em Gênova, lecionando e escrevendo. É também êle apre- 
ciado tradutor e notável conhecedor do grego; em 1949 ganhou - "Prêmio S. Vincent", graças às suas poesias. Escreveu: Resine, Pianissimo, Trucioli.

Escritores da atualidade são Artur Codignola e Emílio Servadio. O primeiro nasceu em Nizza Maríttima e tornou-se conhecido catediático de história na Universidade de Gênova pelas suas numerosas publicações históricas relativas ao Ressurgimento Italiano; o segundo nasceu em Gênova e dedicou-se à psicologia, tendo publicado numerosos livros relativos à sua especialidade.

Poetas e escritores ligures sāo também Adriano Grande, de Gênova, Ítalo Calvino, de Sanremo, e Carlo Bo, de Sestri Levante. O primeiro exerceu diversas profissões e ocupou-se com a poesia, publicando: Avventure (prosas e poesias), Nuvole sul greto, Strada al mare, Fuoco bianco, Ritratto di Genova. O segundo formou-se em letras e foi guerrilheiro; publicou uns volumes cujo fundo é de caráter político ou relativo às guerrilhas travadas no fim da segunda guerra mundial. O terceiro, professor universitário de literatura francesa, colaborou em revistas e jornais, e publicou diversos livros de crítica literária e interpretações de poetas. Mencionamos: Mallarmé, Carte spagnole, Realtà e poesia di Corrado Alvaro, Riflessioni critiche, Jacques Rivière, Otto studi, Antologia di poeti negri e outros ainda.

Enfim, concluímos esta resenha de poetas e literatos da Ligúria com Eugênio Montale (Gènova, 1896). E poeta de tendências herméticas, crítico literário e apreciado tradutor; escreveu em numerosas revistas: Primo Tempo, Fiera Letteraria, Solaria. Foi oficial do exército na primeira guerra mundial, diretor do afamado "Cabinetto G. P. Viesseux", e desde 1947 redator do mais importante jornal da Itália, II Corriere della Sera. Em 1932 foi-lhe conferido o premio "Dell'Antico Fattore" por seus merecimentos poéticos.

Suas obras mais impsrtantes sāo: Ossi di seppia, Occasioni, 47 poesie. Foi chamado o poeta do desespêro, por ter visto a dor em tôdas as coisas: 
Bene non seppi, fuori che il prodigio che schiude la divina Indifferenza: era la statua nella sonnolenza del meriggio, e la nuvola, e il falco alto levato.

Nascido na Ligúria, Montale canta o mar, as estradas abrasadas pelo sol, os rochedos, as hortas cheias de abrolhos, sarças e espinheiros; não vê êle a natureza como cenário grandioso onde se realiza a tumultuosa história humana, mas como uma paisagem hirta, áspera, pedrenta no meio da qual o homem deve andar, levando para a frente sua vida sem esperanças.

Sem dúvida, há algo de novo na poesia de Montale, dura, realista, descontente, rebelde; mas a mesma nota musical, tocada à saciedade, acaba por cansar. Apercebeu-o talvez Montale, que teve êxito invejável e foi considerado um dos mais notáveis poetas desta geração. Pode parecer estranho que, nascido numa terra tão risonha e esplêndida, Montale tenha teimado em ver a natureza quase sòmente sob o aspecto árido e desconsolado. Evidentemente, o poeta, nesta natureza rude, incômoda, hirta de abrolhos, de pedras e cacos de vidro, procura um espelho, uma alegnria de sua dramática vida espiritual.

Meriggiare pallido e assorto presso un rovente muro d'orto, ascoltare tra i pruni e gli sterpi schiocchi di merli, frusci di serpi....

Osservare tra frondi il palpitare lontano di scaglie di mare mentre si levano tremuli scricchi di cicale dai calvi picchi. $E$ andando nel sole che abbaglia sentire con triste meraviglia com'è tutta la vita e il suo travaglio in questo seguitare una muraglia che ha in cima cocci aguzzi di bottiglia. 
1) O espirito interesseiro e utilitário dos Cenoveses, e, portanto, dos Lígures parece ter impressionado também o escritor brasileiro, Silveira Bueno, que no seu esplêndido livro de viagens, "Pelos Caminhos do Mundo", escreve: 'Poucas cidades haverá na terra, mais materializada, mais interesseira, mais agarrada aos bens perecediores da existència, do que Gênova." Silveira Bueno, Pelos Caminhos do Mundo", Saraiva, São Paulo, 1956, p. 158.

2) Não se falou neste artigo de Leon Battista Alberti e de Clemente Rébora; pois, o primeiro nasceu em Cênova, mas sua família era florentina $e$ oscritor não teve relação alguma com Gênova; o segundo nasceu em Milāo, embora sua familia fôsse ligure, e viveu sempre longe da terra de seus pais.

3) E interessante salientar que II Cuore foi traduzido e editado pelo menos treze vêzes no Chile.

- Corazón, Santiago do Chile, 1893, 1919, 1929, 1930, 1938, 1939, 1939, 1940, 1940, 1946, 1948, 1955; Valparaiso. 1935. 